\title{
On the Pseudomyxoma Peritonei.
}

\author{
By L. A. Krivsky. \\ Professor of Obstetrics and Gynacology at the Private University \\ in Petrograd; Head Doctor of the Gyncecological Section \\ of the Obukrov Hospital in Petrograd.
}

(Reccived October 1916.) ${ }^{\mathrm{l}}$

In 1884 , Werth, in his classic paper, described the condition to which he gave the name of pseudomyxoma peritonci. This disease is due to the flooding of the abdominal cavity with masses of gelatinous matter-due to the rupture of a pseudomucinous ovarian cystoma, or to the bursting of the appendix vermicularis, when too much expanded by its mucous contents. Many years elapsed before E. Fränkel (IgOI) reported a second case confirming the possibility of this disease.

From this time began the differentiation of the two varieties of pseudomyxoma peritonei, according to its origin from an ovarian cystoma or from the appendix. The first variety was much earlicr made a subject of more exact study, and many treatises were written dealing with its etiology, method of spreading, clinical symptoms, microscopical structure and malignancy, etc.

In addition to the treatises dealing with this question and usually cited, I should like to mention one other, which is very seldom referred to even by Russian authors, namely the dissertation by Dr. T. D. Eiger, entitled " Materials dealing with the subject of Pseudomyxoma Peritonei," which appeared in 1900 from the Clinic of Prof. A. T. Lebedeff. This paper contained much detailed historical and literary matter, and described three cases treated at the said Clinic.

The conclusions reached by the author as a result of his investigations may be briefly summarised as follows :-(a) Pseudomyxoma peritonei is not an independent disease, but always appcars as a consequence of the bursting of pseudomucinous ovarian tumours;

r. Professor Krivsky, who was a member of the Russian Commission in London during the first years of the war, returned at once to Russia on the outbreak of the Revolution, and has not been heard of since. The Editor has thereforc been unable to send a proof of this paper, which was in script, to Professor Krivsky, and although great care has been taken with the paper in preparing it for press it is possible that some portions of it are not quite clear. 
(b) there are typical adenocystomata which show the peculiarity that their walls are very thin and therefore burst very easily; (c) the contents of the various loculi in adenocystomata are not identical, the secretion in the larger and older cavities being of a watery nature, while in the smaller and younger ones it is gelatinous; $(d)$ the flooding of the abdominal cavity with the contents of the cystoma does not cause myxomatous degeneration of the peritoneum ; an alteration ensues, viz., the formation of new bloodvessels, first in the peritoneum and later in the pseudomucinous masses, which later become divided into compartments and finally disappear.

Collateral with the foregoing process the so-called " implantation" may appear. This is characterised by the appearance on the peritoneum of secondary cystomata, due to the grafting on it of some of the living elements of the primary cystoma. These secondary cystomata produce in their turn pseudomucinous masses. The fact that in some cases the change in the peritoneum is exclusively characterized by chronic inflammation, while in others it is complicated by implantation is explained by the age of the ruptured cystoma. If it is of considerable age and the contents are probably without living epithelial elements, only the reactive inflammation appears on the peritoneum; if, on the other hand, it is of recent formation and elements capable of further growth escape into the peritoneal cavity, the process of inflammation is complicated by implantation. The only correct treatment of this disease is the removal of the ruptured cystoma by surgical operation and of the colloid matter which had escaped from it into the peritoneum. In a number of recorded cases, after the operation the patches of gelatinous matter implanted on the peritoneum, instead of disappearing, continued to spread, thus causing a relapse and necessitating a second operation. The transition of the implanted masses to the atypical neoplasm is quite possible, but it very seldom occurs.

Although I have no intention of dwelling at any great length upon matters which might have a tendency to influence the views held during a period of 14 years, I may add that a year after the publication of Eiger's paper the investigations of E. Fräinkel resulted in the discovery of a now variety of the disease under discussion.

As shown by Paczek, Henke ${ }^{1}$ anticipated Fränkel by describing a case of multiple cystic tumour in the peritoneal cavity, similar to a lymphangeioma, "microscopically the changes in the peritoneum reminded one of the so-called pseudomyxoma peritonei of Worth, 
but as in our case the patient was a man this was not possible. Evidently this was a case of pseudomyxoma peritonei arising in the vermiform appendix."

Following Fränkel's paper appeared others, which confirmed his observations, and cases of this new varicty, viz., pseudomyxoma peritonei due to a ruptured vermiform appendix, can now be counted in tens; thus B. M. Leontieff (1913) reports 22 cases, Winteller (1909) 12, Paczek (IgI2) 9. In my own opinion we must add to the 22 cases of Leontieff those described by the following authorities, viz.: Christian, Trotte, Meriel et Daunic, Rothe, Wilson (two cases), Eden, Paczek, Cagnetto, ${ }^{1}$ and my own, which bring the total up to $3^{2}$.

Bailey (igi6) states that no less than one hundred cases of pseudomyxoma peritonei arising from the appendix have been noted, and cites his own case and those of Castle, Bhanoster, and G. Lewis. In the same paper he mentions another casc of his own which we wish to cite later on.

It has been proved that this diseasc occurs in men even more frequently than in women, for, of the nine cases cited by Paczek, only two were in women.

The discovery of the formation and accumulation of mucus in the appendix in such quantities as to rupture the latter and escape into the peritoneal cavity led pathologists and surgeons to inquire into the causes of the accumulation of the mucus. Papers appeared discussing the conditions of its formation, and a number of investigators undertook macro- and microscopic examinations of the appendix. A little later appeared detailed accounts of these microscopic researches, especially with reference to cysts on the appendix, diverticuli, etc. (see E. N. Vinteller, T. T. Syssoyeff, G. N. Orloff, W. Simon, M. Zondeck, Oberndorfer and others).

Of late authorities on the subject seem gradually to be coming to the conclusion, correctly we think, that the disease has in many cases originated in both organs, i.e., in ovary and appendix, as in the one we cite below, the only doubt being which organ was first attacked. If we admit the discovery in late ycars of cases of this disease having their origin in the appendix, it may be supposed that there were such cases earlier, but that the changes in the appendix were not noticed, being obscured by the changes which had taken place in other abdominal organs by the deposition of the mucus in various parts of the abdominal cavity.

The patient, Elisabeth R., a married woman, was admitted to the Obukhow Hospital on the 15th October, 1913. She was then 37 years of age, had been to ycars married, but had never been

1. See Paczek, l.c., p. 9, et seq. 
pregnant; menstruation began at the age of 14 years, and occurred regularly every month for four days, up to the 26th September, I913, and then ceased. She stated that she had been ill for some six months, and was an in-patient of one of the hospitals in Petrograd from September 13th till the and or $3^{\text {rd }}$ of October; she was there treated for swelling of the abdomen and chronic diarrhoea, which complaint she had been free from during the three weeks prior to her admission to the Obukrov Hospital. On admission her temperature was $97^{\circ} 4^{\circ} \mathrm{F}$, and the pulse-rate $\mathrm{I} 20$; the heart was a little wider than normal, but the beating was distinct; there was evident ascites, and the feet were swollen; the weight of body was slightly under 6 stone.

The abdomen was much distended with ascites, and the abdominal organs were not to be felt. The circumference of the abdomen, measured at the level of the navel, was $82 \mathrm{~cm}$., there was no odema and defæcation was normal; temperature $97^{\circ} 9^{\circ} \mathrm{F}$.

The daily condition of the patient subsequent to this second examination may be briefly summarized as follows :-

I6 October : T. $97^{\circ} 7^{\circ}$ F., p. 96 ; defæcation once, action formed, normal in appearance; the quantity of urine $500 \mathrm{cc}$., with a specific gravity of I023, and no albumen or sugar; in the evening T. $968^{\circ} \mathrm{F}$.

I7 October: T. $975^{\circ} \mathrm{F}$; the previous evening the patient had a slight attack of diarrhœa with pain, which ceased later on and she felt better; in the evening T. $984^{\circ} \mathrm{F}$.

18 October : T. $97^{\circ} 7^{\circ} \mathrm{F}$. in the morning; defacation twice, motion porridge-like.

I9 October: T. $97^{\circ} 9^{\circ} \mathrm{F}$. in the morning, $96.8^{\circ} \mathrm{F}$. in the evening; circumference of the abdomen $8 \mathrm{I} \mathrm{cm}$, diuresis normal; defacation twice, motion formed, no cough.

20) October : T. $97^{\circ} 7^{\circ} \mathrm{F}$. and $96^{\circ} 8^{\circ} \mathrm{F}$, pulse 86 ; diaphragm forced upward; ascites marked.

22 October : The temperature the same; ascites undiminished; the circumference of the abdomen $82 \mathrm{~cm}$. On tapping the abdomen only a few drops of thick sticky fluid were drawn off. The patient was transferred to the gynæcological department.

The circumference of the abdomen at the level of the navel was $8 \mathrm{I} \mathrm{cm}$. (ascites), no discharge from the vagina, the cervix uteri is closed, the uterus is anteflexed, the fornices stretched and not tender. Through the left anterior fornix high up there was an elastic tumour very difficult to reach; a more detailed examination was impossible owing to the ascites; T. $984^{\circ} \mathrm{F}$.

Some days passed without any change; the temperature was normal, but the patient complained of difficulty in breathing in consequence of increasing ascites.

On the 3oth October, 1913, the abdomen was opened in the 
middle line under mixed narcosis (ether $80^{\circ}$, chloroform $8:$; duration of the narcosis I hour 20 minutes). On opening the peritoneal cavity lumps of gelatinous matter began at once to escape. These amorphous lumps of jelly were larger than the palm of the hand and shaped like a jelly-fish, being transparent at the periphery and muddy in the centre; they were lying freely between the intestines and were not without difficulty removed from the peritoneal cavity. The peritoncum of the intestines and of the abdominal wall was a little injected, but there was no sign anywhere that the above-mentioned gelatinous matter was adherent to it.

There was a thin multilocular cystoma of the left ovary, about the size of the head of a new-born child, containing gelatinous matter similar to the lumps in the peritoneal cavity. There were no adhesions. Owing to the bursting of the wall of the cystoma in several places the gelatinous matter had exuded and adhered to its surface. On the upper surface of the cystoma lay the salpinx, very much enlarged and thickened, but in other respects normally developed. The pedicle of the cystoma was tied and the latter removed, together with the left tube, after which the stump was sewn ovcr. The right appendages, although of normal size, were also cut away.

When removing the lumps of gelatinous matter from the pouch of Douglas and from between the intestines special examination was made of the peritoneum with a view to ascertaining to what extent they had spread in it, but, as already mentioned, no sign of such was discovered. Particular attention was paid to the appendix, which appeared to have undergone considerable change; it was much thickened and of oval shape, resembling somewhat a large plum; it was not adherent to any other part and projected into the peritoneal cavity. The removal of the mucus adhering to it led to the discovery of three punctures, which, as well as its cavity, were filled with mucus similar to that above mentioned. These punctures, the edges of which were thickened and transparent, were about $\frac{3}{4} \mathrm{~cm}$. in diameter, and situated close to one another about midway between the two ends of the appendix. The latter was removed in the usual manner; it contained no excrement, and no changes were observed in the mesentery.

The abdominal cavity was with some difficulty cleansed of the foreign gelatinous masses, which, when collected, were found to have a bulk of no less than $3,500 \mathrm{cc}$.

The uterus retained its normal shape. The abdominal wall was sewn up as usual in three layers.

The appendix measured $6.5 \mathrm{~cm}$. in length, $3 \mathrm{~cm}$. in breadth and more than $2 \mathrm{~cm}$. in thickness of wall; it was filled with mucus, but 
contained no excrement; the cavity was evidently closed at the part nearest to the cæcum.

Recovery was normal, and 27 days after the operation the patient left the Hospital suffering only from very slight ascites.

In May 1914 the patient, who had visibly improved in health, stated that she felt well and had no cause for complaint. On examination per vaginam, a small thickening on the right of the uterus was discovered, which was suspicious from the point of view of recurrence.

Fourteen months after the operation I saw the patient, who complained only of severe headaches during menstruation, which was quite regular in spite of the absence of the ovaries. The scar caused by the operation was in a perfectly healthy condition, and there was no sign of tumour or ascites in the abdominal cavity. An examination per vaginam proved the uterus to be in a normal position, but it seemed a little enlarged. In the right posterior fornix there was a very small thickening of the utero-sacral ligament which limited the mobility of the uterus; this was probably due to adhesions. On the left side, in the region of the stump of the left appendages, there was also a thickening smaller than on the right side, movable and painless.

The gelatinous lumps, which were lying unattached in the peritoneal cavity, were not examined microscopically, and it is impossible to state whether they contained any epithelial matter.

On examination of sections of the ovarian cyst the cylindrical epithelium was distinctly noted to be well preserved, with here and there goblet cells, producing mucus, which lay adjacent to them in large quantities. The epithelium was in places detached, partly retaining its normal shape, partly degenerated and with picuetic appearance in the nucleus; further, there was to be seen the stroma of the connective-tissue, infiltrated with lymphocytes and polyblasts which were chiefly on the periphery of the vessels, the endothelium of which appeared to be swollen. Isolated formed elements occurred even at some distance from the vessels between the collagenous fibres; between the fibres of the connective-tissue were dispersed elements of muscle tissue in small quantities, while fibroblasts were few in number; here and there swelling, even hyalinization, of the walls of the vessels was noted.

Pieces were taken from the appendix in two places; firstly, from the distal end, which was distended and had not undergone much change; and, secondly, from the callous edge of one of the openings.

In the first named the epithelium was in parts in a state of some preservation, here and there it was cylindrical, or quite absent, being exfoliated to a great extent; the submucous layer was 
characterized by an accumulation of lymphocytes, somewhat diffuse and sometimes in the shape of small follicles with rather limited contours; further, there was a layer of thick connective-tissue, poor in fibroblasts, and under this the muscle layer, here and there replaced by the elements of new connective-tissue, rich in cellular forms; there was no sign of Lieberkühn's glands, but there was a profusion of blood-vessels, the walls of which were thickened, and here and there, as in the stroma of connective-tissue, were places with hyalin change. 'The endothelium of the vessels was swollen.

Both in the mucus between the connective- and muscle-tissues and in the thickened serosa were discovered precipitations of lime, but not in any large quantities.

For the purpose of staining the hematoxylin eosin, Van Giesson, Giemra ${ }^{1}$ was employed, and for determination of the mucus the micro-chemical reaction with the mucicarmin stain $^{2}$ was employed, with positive result, showing the gelatinous substance in dark pink colour.

The point we hoped to settle by the microscopical examination, whether the disease of the appendix began on the outside and proceeded inwards, or whether the mucus with which it was filled perforated the walls of the appendix, was not definitely decided; but from a theoretical point of view the first hypothesis is very difficult to admit. Therefore we had in our case a pseudomucinous cystoma of the left ovary, the wall of which was very thin and was broken and then a mass consisting of the separated parts of the cystoma forced its way into the cavity of the peritoneum spreading freely between the intestines and litle by little filling the whole cavity-. the quantity without counting the loss was no less than $3,300 \mathrm{cc}$.-clinically it gave the impression of acute ascites, causing suffering to the patient and compelling her at last to seck medical advice.

When the wall of the cystoma was ruptured we could not determine, but it was certainly not less than six months previously, because the patient at that time noticed the swelling of the abdomen; whether it took place suddenly or gradually it is also impossible to ascertain, for the patient did not remember anything happening to her which could be attributed to the rupture of the wall of the cystoma.

What was the reaction of the peritoneum of the abdominal wall and of the intestines to the gelatinous matter which had escaped into the abdomen ?

1. 20 cc. of mixture of azur 2 (water solution in $1:$ woro) and usin W.li. (water sol. $1: 1000)$ in $80 \mathrm{cc}$. of water.

2. Spirituous solution for $15-30$ minules, before that hematoxylin heyer for 10 minutes. 
As was seen at the operation, it consisted simply in the enlargement of the blood-vessels of the peritoneum, i.e., hyperæmia, but we did not find on the latter any places where the gelatinous mass was adherent and had continued to develop.

Unfortunately the unattached gelatinous masses were not microscopically examined, and therefore it is improssible to decide definitely whether they were inclined to organization; it may, however, be fairly presumed this was so, for in the centre of these almost entirely transparent masses, there were to be seen with the naked eye, whitish cloudy spots with remarkable little fibres spreading out in all directions.

These masses were nowhere adherent to the peritoneum.

After the diagnosis of the pseudomyxoma of peritoneum particular attention was given to the condition of the appendix, and though it was definitely settled that these gelatinous masses had their origin in the cystoma of the left ovary, yet the appendix appeared to have taken part in the process and was changed as previously described.

Thus in this case we have two distinct causes of pseudomyxoma peritonei- $(a)$ the burst wall of the cystoma of the left ovary; and (b) the appendix, which latter represented a cyst-like formation, filled with mucus which escaped into the peritoneal cavity through the three perforations already mentioned.

The question naturally arises as to which was the seat of the primary affection, the cystoma or the appendix, and this question we shall now deal with.

In the first place, the number and bulk of the floating masses which escaped into the peritoneal cavity cannot determine their origin, for it is known that in the case of pseudomyxoma peritonei, having its origin in the appendix, the quantity of mucus can also be very large. Even the microscopical examination of the mucus would hardly allow of a definite diagnosis, for in both forms of pseudomyxoma the epithelium must be cylindrical in shape or depressed into a cubic form with a number-larger or smaller as the case may be-of the goblet-like cells producing mucus.

In the second place, if the primary process was in the appendix it would be more likely to affect the right ovary and not the left one as in the case in point.

Then again, from enquiries made of the patient, we know that the swelling of the abdomen started about six months before she came to the hospital, while it was not till later that she suffered from almost continuous diarrhoea, which ceased only three, weeks before her arrival at our Hospital. These symptoms, in our opinion, are explained by the supposition that the gelatinous masses had been collecting in the peritoneal cavity for a long time, that is, 
prior to six months preceding the operation (during which time the abdomen was swelling), and then the process was either localized or, anticipating our conclusions, we may say that it began to form independently in the appendix and was accompanied with diarrhoea.

Although the microscopical changes in the appendix do not give support to any theory relative to whether the disease started on the outside wall and proceeded inwards, or vice versa, the second theory seems more logical and truer in a pathological sense, because otherwise it would have to be presumed that the gelatinous masses, not being adherent to the peritoneum anywhere else save the appendix, could obtain corroding or even perforating power sufficient to pierce the wall of the appendix; this we do not find anywhere in descriptions of similar cases.

Taking all this into consideration, we think that the appendix cannot be considered the point of origin of the disease because it was attacked after the cyst of the ovary appeared; further, it cannot be supposed that the appendix was attacked secondarily by means of the protruding action of the gelatinous masses, for if this were so it would have to be presumed that these masses could perforate the walls of the appendix.

The two possibilities which remain, therefore, are either that both in the cyst of the ovary and in the vermiform appendix changes identical in character took place simultaneously, and a retentive pseudomyxomatous cyst was formed in the latter, or the primary seat of the disease was the cyst of the left ovary, which, bursting, led to general peritoneal dissemination. This gave rise to secondary, possibly inflammatory, changes in the region of the appendix, causing a cyst, filled with mucus, which in time perforated its walls.

This last theory would seem to be corroborated by the literature extant dealing with pseudomyxoma of the peritoneum arising in the appendix and the origin of cysts in the latter (Oberndorfer, Vonheler, Ssyboieff, etc.). We know, on the authority of these authors that changes in the appendix produced by inflammation may cause cystic or similar growths.

In support of the theory of a simultaneous process of discase going on in the two organs it may be advanced that this theory is in no way nullified by the preceding one, and it docs not exclude the idea of the absence of these diseases in the appendix. Moreover, it may also be presumed that the disease in the latter organ began to develop at the same time as in the cyst of the ovary, but progressed imperceptibly, and finally marked its appearance by diarrhcea.

The latter was caused, as we suppose, by the escape of the mucus from the appendix into the intestine before it had become isolated from the cæcum. 
In view of the foregoing we come to the conclusion that the process in the cyst of the ovary and in the appendix were of identical origin and began to develop almost, if not quite, simultaneously.

Researches into the literature of the subject confirmed in the main the correctness of our views.

Certain indications were, however, discovered which might easily have led us astray, and with these we shall deal in greater detail later. Some cases were described of psudomyxoma peritonei arising in the appendix, which proved that men also were subject to the disease and that it was not necessarily the outcome of a cystoma of the ovary. This led to further investigations into the cause of cysts in the appendix, and more attention was given to this latter organ, and cases were instanced in which the disease was present in the cystoma of the ovary and the appendix simultaneously.

As one instance of this we may mention the following cases treated by Rathe:-A woman, 4I years of age, who had given birth to nine children, was diagnosed as suffering from a cyst of the left ovary. She was operated upon in November 1909, when cysts as large as a man's head were discovered in both ovaries, the abdominal cavity being flooded with gelatinous masses; the cysts were removed. In March 1912 a knotty growth about the size of a hen's egg was observed on the scar of the abdominal wall ; it was of gelatinous formation and protruded from the scar into the peritoneal cavity; this growth was acknowledged (by Bondy) after microscopical examination to be a case of pseudomyxoma. No further growths of a similar nature were found in the peritoneal cavity. A third operation, which was performed on October 23rd, I912, gave no sign either of ascites or free gelatinous masses. There were, however, a number of tumours on the peritoneum of the bladder, the small intestine, the omentum, and largest of allabout the size of a pigeon's egg - on the ovarian pedicles. Very decided changes were also observed in the appendix. All these growths upon microscopical examination proved to be pseudomyxomatous in structure.

When Rathe demonstrated this case Bondy suggested that the pseudomyxoma ovarii et peritonei might have been caused by the accumulation of the mucus in the appendix, and he advised attention being paid to this organ.

On the occasion of the second demonstration of his case by Rathe, Bondy considered it imperative once more to state his opinion, and in support of it he adduced one case of pseudomyxoma peritonei with a large cyst of one ovary and smaller one of the 
other, in which he had examined the appendix and found there changes corresponding to those in the ovaries.

A similar view was also taken by $R$. Meyer with reference to a case which was demonstrated by W. Nagel (Zentr. f. Gyncek., ig12, p. $\mathbf{1}, 583$ ). Mayer raised the point as to whether in this case of pseudomyxoma peritonei it was possible to exclude the idea of the appendix being the primary seat of the disease since the gelatinous tumours of the ovaries seemed to be but secondary causes.

Rathe, in citing this opinion of R. Meyer, thought it necessary to dissent from it as unproved. He admitted there were many authorities who considered the appendix to be the organ primarily attacked, but his own opinion was that it was the ovary, and that the appendix was only a secondary seat of the disease.

This new demonstration of Rathe's case provoked very animated discussion.

Biermer, in whose department the case of Rathe's occurred, asserted that there was no other metastasis than to the wall of the abdomen, and that, although the appendix was not intentionally overlooked, it did not attract particular attention, and he consequently could imagine that there was no change in it.

Peiser also expressed the opinion that the ovary was first attacked and the appendix subsequently.

On the other hand, L. Fränkel, Klaatrch, Asch and Bondy took a contrary view and considered it highly improbable that the wall of the appendix was perforated from without by the myxoma, as would have been necessary in order to prove the metastasis of the disease from the ovary.

Whether the appendix was in this case the primary seat of the disease could not therefore, owing to difference of opinion, be definitely determined.

The idea that the issue of the disease was more favourable when arising in the appendix than in the cystoma of the ovary, was supported by the fact that after the removal of the primary seat of the disease (i.e., the appendix) the patients were less liable to rclapse than if the metastatic tumours of the ovary were removed and the appendix -the supposed but not proved primary seat of the disease-retained.

In all future cases in which an operation is performed a detailed examination of the appendix should on no account be omitted, as it may be the primary seat of the disease.

Bondy goes still further in his suppositions, based upon this case of his, and even advances the hypothesis that every case of pseudomyxoma peritonei, originated in the appendix, the ovaries and peritoneum being but secondary seats of the disease.

This hypothesis seems to us, however, an untenable one, being 
the result of a too audacious generalizing based upon isolated cases.

Our previously mentioned conviction that, in our own case, the disease had two distinct and simultaneous places of origin was confirmed by some new facts, which we should like to cite.

T. W. Eden has described a case upon which he operated resembling Rathe's and our own. This case was interesting because when the ovary was first attacked changes occurred in the appendix, quite independent of the ovary, similar to those observed in several cases of pseudomyxoma arising in this organ.

This case was more allied to Rathe's than to our own, in which at the first operation, changes were noted to have taken place in both organs. The patient, a woman, 46 years of age, was operated upon for cystoma of the right ovary. The operation discovered, besides the cystoma, a large quantity of clear yellow jelly in the peritoneal cavity which it was found impossible to remove entirely owing to its firm adhesion. The uterus and the left appendages appeared to be normal, but no special attention was paid to the appendix. Within two years and four months after the operation the abdomen began to enlarge, and a second operation was performed. This discovered a cystoma of the left ovary, similar in character to that removed from the right ovary, which had burst and filled the entire abdominal cavity with colloid matter. The peritoneum was red, thickened and covered with the gelatinous mass, which was adherent to it ; there were no changes in the uterus, but the appendix was enlarged cylindrically from the tip to within about a centimetre of the crcum, and was about the size of the little finger; when it was cut off a quantity of gelatinous matter escaped similar to that in the ovarian cyst.

Microscopic examination of the wall of the ovarian cyst showed high palisade epithelium in great abundance, and for the most part in an advanced stage of degeneration. Here and there wellpreserved goblet-cells distended with secretion were seen ; generally, however, the cell bodies were converted into a coarsely granular débris, the nuclei at their base being well preserved. On examining the wall of the appendix the greater part of the mucosa was found to have been destroyed; patches remained, however, which showed aggregations of coarsely granular amorphous material adherent to their free surface-representing the colloid. The epithelial cells themselves were either distended to bursting point with secretion, or the bodies were destroyed, leaving the nuclei either alone or along with a certain amount of granular amorphous material. It was quite clear, from these appearances that the colloid material contained in the appendix was the product of its own mucous 
membrane, and was, therefore, in its origin, independent of the ovarian cyst.

The simultaneous and independent occurrence of this colloid disease in the ovary and the vermiform appendix has not, I believe, been previously recorded. The disease is epithelial in origin, and the fact that it may simultaneously arise in two types of epithelium of such divergent characters as that of the ovary and the appendix is curious and interesting.

The analogy between our case and the one just cited is complete with the exception that, in the first place, the disease appeared later in the appendix, corresponding in point of time with the appearance of the secondary tumour, while in our case it corresponded with the primary disease of the ovary. Moreover, the disease in the case of Eden's patient was not so fully developed as in our own; the cyst of the appendix in his case was very far from the bursting point, while in our case there were three perforations of the appendix, seeming to prove a more violent and virulent progress of the disease.

Whether this will be bad for the patient in the future is difficult to say definitely, as the operation was only performed two years ago; but, on the other hand, in Eden's case, the appendix was not examined at the first operation and might have been attacked beforehand.

In our case the cystoma of the left ovary, the right appendages and the appendix were removed at the first operation, which justified the hope that there would be no relapse. We could not be quite certain of this because some gelatinous matter might have been overlooked and remaining in the abdominal cavity caused later a recrudescence of the disease.

We had just completed our paper when we happened to learn of one case more, similar to our own; namely, that of T. W. Bailey.

The author describes his case and cites those of Eden, Wilson and Rathe above mentioned, which he calls cases of pseudomyxomatous appendix, complicated by an ovarian cyst of large size. In all cases there had becn a rupture of the ovarian cyst with resulting pseudomyxoma peritonei. The case is very interesting because of the evidently primary involvement of both ovary (left) and appendix; symptomless rupture of the ovarian cyst and the complete dissemination over the peritoneal cavity and its contents following this liberation of pseudomucin.

The question of the malignancy of the pseudomyxoma of the peritoneum arising from ovarian cystoma has been dealt with by Pfannenstiel (Werth's Handb. der Gyn., Bd. IV, s. r6o), and the conclusion at which he arrives is, in the first place, that though a complete recovery or, at any rate, the repression of the discase for a 
long period, may be possible, so favourable an issue is unfortunately getting rarer and rarer; and, in the second place, that a differentiation must be made between those cases in which the disease is of rapid growth and those in which it has taken years to develop, as an example of which he cites the case of FritschOlshausen, the patient dying $17 \frac{1}{2}$ years after the first operation.

According to Eiger the chances of a complete recovery depend very much upon the age of the cystomata which are the cause of pseudomyxoma peritonei ; in cystomata of recent date, in which the epithelium is more prone to growth and the production of mucus a more rapit relapse is to be expected.

Lahm, in his paper entitled "On the hystogenesis of the pseudomucinous cystomata of the ovary," discusses their origin from Walthard's cells, which occur in the normal ovaries. He recognizes when the cystoma is removed from the diseased ovary the importance of an examination of the apparently healthy one; this would render possible observation in their initial stage of changes similar to those which had taken place in the diseased ovary.

Lahm further says that pseudomucinous cystomata and Walthard's accumulation of cells may be a predisposing cause of the production of solid or glandular carcinoma. He does not, however, touch upon the subject of malignancy of the metastases of the pseudomyxomatous masses themselves, although this subject is of very great interest to us in the determination of the malignancy and cause of metastases and particularly of relapses of the disease, which have been observed especially in cases of pseudomyxoma of the peritoneum (see for example Rathe's case and others).

Polano, in describing his case of pscudomyxoma peritonei and cystomata ovarii, notes the peculiarly sharply progressive and destructive character of the disease, both in an anatomical and clinical sense; he suggests at the conclusion of his paper that for all practical purposes the disease must be divided into two classes : the first is the cystadenoma pseudomucinosum peritonei simplex, which represents a simple superficial metastasis arising through the implantation (Olshausen's "Implantation Metastase"): the second, the cystadenoma malignum pseudomucinosum peritonei, the most typical case of which is his own. The difference between the malignant and simple kinds lies only in the degree of liability to relapse.

One case of special malignancy with metastases penetrating the greater part of the abdomen and spreading to and perforating the intestines, was described by M. W. Meyer, who, basing his opinion on this case, considers that it contradicts the idea of the benignancy of this tumour; on the other hand, he cites another case, in which the 
patient was 65 years old with metastases on the peritoneum but benign in character.

From among the earlier authorities we can cite Peters, who gives his opinion as to the unfavourable prognosis of the pseudomyxoma peritonei ex appendice.

Shumann also deems pseudomyxoma peritonei to be a dangerous disease owing to its disposition to relapse and the producing of cachexia, and classes this disease with the special kinds of carcinoma, i.e., with colloid cancer.

S. Wiener describes his case, in which at first a pseudomucinous cystoma of one of the ovaries, quite benign in character, was removed; the other ovary was normal, but two years afterwards there appeared in it an immense cystoma of the same shape which, on microscopical examination, was found to be quite benign, although there were ascites and a dissemination of gelatinous masses, which could not be removed from the peritoneum. Two months after this operation there were symptoms of increasing ascites and the patient died; there was no autopsy. The author thinks that the process in the second ovary was quite independent of that in the first.

Cases similar to this seem to us very important and demonstrative in the sense that there appears in the organism some peculiar predisposition to identical neoplasms, arising in various organs and at diffent times. For example, in Wiener's case, as also in many others, the disease appeared first in one ovary and then in the other, and both, in Eden's case and our own, in one ovary and the appendix. Further, Wiener's case is interesting because a tumour benign in a histologica] sense, becomes very malignant in its clinical course.

In view of this fact Wiener puts the question as to how the second ovary should be dealt with when removing the cystoma of one of the ovaries; he suggests cutting out a piece from a part which looks at all suspicious and examining it before closing the abdomen.

Wiener, from his own experience, further confirms, in the following conclusions, Pfannenstiel's view upon the prognosis for cystomata of ovaries. One-third of all proliferating lumours of the ovary have an incontestably malignant character ; in the other twothirds the malignancy is potential. The question as to malignancy can only be determined by the clinical course of the disease. Usually these tumours are histologically benign, but may cause death by the perforation of the walls of the cystoma allowing its contents to escape and resulting in the spreading of metastases on the peritoneum. Every tumour of the ovary should be removed by laparatomy as soon as possible with the contents absolutely intact. If it has burst of itself, then the sooner the operation is 
performed the better. When removing a unilateral cystoma of the ovary, the other ovary, macroscopically normal, must be left, if the cystoma does not contain any incontestable malignancy or excessive papillomatous growth. All patients after the removal of the one ovary in consequent of cystadenoma, must be periodically examined with respect to the remaining ovary.

Subsidiary to his own case, Wiener quotes Nicholson's, which was examined in L. Pick's laboratory. A woman, 60 years old, had an absolutely benign pseudomucinous cystadenoma of the ovary, while at the post-mortem all the symptoms of malignancy, such as the spreading of the disease to the neighbouring tissues and organs with protrusion of the cervix of the uterus, and multiple metastases by means of the blood-vessels to the lungs, which produced a very rapid fatal issue. This case seems to Wiener to be unique.

Further, A. Hahn in his dissertation proceeding from the same laboratory (L. Pick's), discusses in detail the question as to the manner in which the walls of a pseudomucinous cystoma are perforated. According to him there are to be seen here and there a separation of the parallel sheets of the connective-tissue by accumulation of transparent matter, very lightly stained by eosin. Those places in which the solid connective-tissue has been replaced by the colloid matter coming from within, are most liable to rupture; the blood-vessels are without surrounding tissue and seem to be quite isolated, gigantic polynuclear cells are visible.

Hahn finishes his paper with a list of cases which were collected by him, which he does not pretend to be quite complete, and although many other cases have been described since the publication of his paper, particularly those of pseudomyxoma peritonei arising from the appendix, we should like to cite his account which characterizes the prognosis of this disease. Out of 60 cases collected by him 23 died, i.e., $39 \%$; only in a very few cases patients who had been operated from four to nine years previously were traced, the greater number were of no longer date than a year or even a few weeks.

Further, Eden notes that "regarded as bordering on malignancy many ovarian cases are on record where complete recovery has followed an operation, which must be called partial, owing to the difficulty of removing the colloid adhering to the peritoneum; in the present case the patient has remained well up to the time of writing, one year and eleven months after the operation."

Quite unique is the opinion of W. Nagel, who, at the VIth International Congress of Gynaccology and Obstetrics, held in Berlin in r 912 , demonstrated one example of myxoma of the ovary.

According to him the gelatinous contents which filled the separate cavities of the cystoma of the ovary and escaped into the 
peritoneal cavity and which clinically consisted of pseudomucin, appeared to be not of epithelial, but of connective-tissue origin.

He therefore considers this disease to be benign, which fact is confirmed by its clinical course. Unfortunately Nagel has not explained his hypothesis to an extent sufficient to allow of our forming a definite opinion. Probably at some future time he may supply us with more facts, which will enable us better to judge of the correctness of his views. We cite his opinion at present for the purpose of showing that this author had to invent a new hypothesis as to non-epithelial origin of this tumour in order to prove the benignant nature of the disease.

While the pseudomyxoma peritonei arising from a cystoma of the ovary has according to the majority of authorities a bad prognosis, the cases arising from the appendix have a mote favourable one; which fact is confirmed by those who have written upon the subject. B. M. Leontieff, for instance, collected 21 cases, his own making the 22nd, and to these we, of course, under correction, must add those of Christian, Trotter, Meriel and Daunic, Rathe, Wilson (two cases), Eden, Paczek, Cagnetto, our own case bringing the total up to $3^{2}$.

According to T. M. Pikin the pseudomyxoma of peritoneum is in the pathological sense benign, but clinically is not an innocent disease.

Paczek, who cites from the literatude on the subject ten cases of pseudomyxoma peritonei arising from the appendix, emphasizes the difference between this kind of disease and that arising from the cystoma of the ovary. In the first kind the prognosis must be absolutely good. Although the epithelial cells escape from the appendix with the gelatinous masses, they are not, according to Oberndorfer, liable to rapid growth, and while they may remain a long time do not produce new tumours.

B. M. Leontieff is of much the same opinion in considering the pscudomyxoma of the peritoneum arising from the appendix to be a benign process.

Bailey says that "there is no record to my knowledge of malignancy following a pseudomucin cyst of the appendix, but by the plastic peritonitis and mechanical interference which follow such an extravasation equally dangerous conditions may develop."

What prognosis, however, can be made in cases in which both causes of pseudomyxoma peritonei are present? There are very few such cases, probably owing to the fact that formerly in describing cases arising from the ovary no attention was paid to the appendix, or it was presumed to have been attacked by the disease in the same way as the other organs of the peritoneal cavity. Among those cases in which both appendix and ovary 
are affected, there is not one in which it can be said that the appendix was primarily attacked; moreover, as in cases arising from the ovary the prognosis is worse than in those arising from the appendix, the prognosis in such cases must be made cautiously and perhaps a recurrence is more to be expected.

Very interesting is the question of the malignancy of pseudomyxoma of the peritoneum, for, in many cases, which ended in death, there was proved to be a total absence of really malignant growths, and besides there was no metastasis of the gelatinous masses. These latter getting malignant become progressive in character and give rise to metastases, remaining the while microscopically similar in structure to the benign cases (see Polano, Rathe and others).

Evidently a final decision upon this matter will not be arrived at until the question of the rtiology of the malignant tumours become clearer. Further microscopical and experimental researches may explain how the same gelatinous matter in some cases manifests a destructive quality.

We had just completed our paper when we happened to learn of a dissertation by Dr. Erik Ahlström of Stockholm. Although it is not of quite recent date, being written in I909, it contains details relating to the gelatinous cystomata of the ovary and the changes arising on the peritoneum after their rupture. We quote from this paper at length because it has not been referred to before.

This paper, which is in the form of a monograph, contains a historical sketch in which the question as to the correctness of the nomenclature of the disease is discussed.

Cases collected by the author from the various clinics of Sweden are described.

In nine of the cases the changes in the peritoneum were microscopically examined and they are described fully; the other I9 cases were only clinically observed with, in some of them, a microscopical examination of the ovaries only. These nineteen cases are tabulated but not described in detail. The author further deals with the pathological anatomy of the cystomata and the changes on the peritoneum from the macro- and microscopical standpoint, and completes his paper with a clinical study of the disease exemplified by some very fine reproduction of the microscopical preparations.

Discussing the question of the metastases of the epithelium and the spread of them on the peritoneum, the author relates that in two of his own cases, as in the cases of Eiger and Schumann, the epithelium appeared of a clearly carcinomatous character, but in other. cases it was quite impossible to ascertain from the anatomical peculiarities of the epithelium of the burst cystoma and the metas- 
tatic tumours on the peritoneum, the liability of the tumour to cause metastases. The solution lies apparently in the different capacity of the epithelium of the gelatinous cystomata to proliferate; this liability is not recognizable in the present state of microscopical examination; moreover, in various cases, the organism does not possess the same degree of resistance, particularly the resistance of the peritoneum, when the epithelium of the burst cystoma escapes into the abdominal cavity.

Owing to these circumstances although the gelatinous cystomata are anatomically benign like the ordinary pseudomucinous cystomata, they must be considered as occupying a position between the benign and malignant tumours.

As regards the nomenclature of the pseudomyxoma peritonei, the author does not agree with it, for many reasons : it does not explain itself. Authorities, he claims, have given this name to different diseases, and he in his microscopical preparations proved that the most important are the metastases of epithelium, but not the process of organization, which was advanced in the first place by Werth. The author prefers to cancel this nomenclature, giving to each case its proper name, including the different parts attacked, for example-a gelatinous cystoma with bursting and forming of metastases on the peritoneum, growing into the latter. If no microscopical examination took place, it is better to employ the term "gelatinous changes of the peritoneum" than the first mentioned.

Personally we are more interested in the question of the participation of the appendix in this disease and in the conclusions come to by the author.

He observes that the term pseudomyxoma peritonei has been used in cases of men, in whom there were gelatinous deposits on the peritoneum, arising from the appendix, which had dilated to form a cyst and then burst.

Ahlström in three cases of his own found definite changes in the appendix simultaneously with the typical picture of the pseudomyxoma peritonei after the bursting of the gelatinous cystoma.

In the first of his cases (p. 30 and foll.) the changes on the peritoneum were not very marked, and the gelatinous masses were lying mostly free in large quantities in the peritoneal cavity, being adherent here and there, including the exterior surface of the cystoma and the right tube; it was also noted that the appendix was distended like a cyst by mucous. "The latter must be taken as a metastases of the epithelium arising from the cystoma of the ovary; this cyst was not on the surface of the appendix but was covered by the peritoneum and by the muscle tissue; it is quite clear that the cyst occupied the place of one of two muscle sheets, 
which were to be distinctily seen in places adjacent to the cyst." The author suggests that the metastasis from the ovary into the appendix had penetrated through the lymphatic vessels.

As the cystoma of the ovary and also the unique potentially proved metastasis in the appendix were removed, it may be supposed that the organism itself overcame the changes on the peritoneum; this is proved by the absence of a recurrence of the disease four years after the operation.

In the second (the 7 th case of Ahlström, p. 59) it was impossible to find on operating the bursting place of the cystoma, which burst during the operation; the tumour was adherent to the anterior wall of the abdomen and there were on the peritoneum deposits of the gelatinous matter and a ruptured cyst of the appendix was also found; this cyst, judging by its epithelium and contents, was identical in nature with those in the cystoma of the ovary.

The cyst of the appendix was very interesting because the appendix was dilated in the form of a cyst only in the middle. The author considered that this could not be due to a simple blocking of that part of the appendix adjoining the crecum, but was caused by the contents of the ruptured cystoma of the ovary, having penetrated the walls of the appendix, gradually causing it to bulge in the direction of the lumen. The muscle layer had undergone considerable change, sufficient to explain the possibility of the bursting of the wall of the appendix.

In this, as in the previous case, there was no recurrence, although a period of two years and three months had elapsed since the operation; this was probably due to the fact that the primary seat of the disease has been removed.

The eighth case is a typical left gelatinous cystoma of the ovary, which had burst some time previously; there was also a ruptured cyst-like tumour in the appendix with the epithelium and gelatinous contents similar to those in the cystoma of the ovary; there were also changes in the omentum and on the peritoneum.

Further (p. 45 et seq.) describing the changes in the peritoneum after the bursting of the cystoma, which appeared as multiple cystlike tumours, Ahlström notes that the appendix and the adjacent part of the cæcum are the places where these tumours very frequently arise. He cites also the case of Schlegtendal, one case of Peters' and one of Kret Schmar's.

"In these cases, as well as in all others, since described, it is seen macroscopically, that there are superficial tumours on the peritoneum, quite distinct from those inside the organ, which are covered by the peritoneum. In three of my own cases, in Westphalen's and the second case of Schumann's, on the contrary, it was possible to ascertain without the microscope that there were 
secondary gelatinous cysts in the appendix itself, covered by the peritoneum." Something similar was observed in the author's fifth case, and also in Hirst and Marchand's cases, not in the appendix, but in the cyst-like metastasis in the wall of the intestine and in the appendix epiplöica."

The author explains the frequent occurrence of these metastases through implantation in the region of the appendix and in the pelvis by the fact that, by the bursting of the cystoma the lumps of gelatinous matter with the epithelium sink into the lowest places of the peritoneal cavity.

Further discussing the question of the metastases, he admits the so-called sub-peritoneal transfer of the metastases in those cases in which the peritoneum covering the secondary growth was unchanged. In these cases, according to him (p. 185 ), the absorption into the lymphatic ducts and the further transfer of the epithelial elements is the only explanation which can be admitted.

In all these passages we have quoted he considers the growths as of a secondary nature or as metastases, and only in rare instances (see p. 195) esteems it impossible to settle by an anatomical examination whether there are metastases due to implantation or new tumours.

Nowhere, however, does he mention the simultaneous appearance of the process in the different organs or the liability of the organism to the formation of tumours in various organs.

With regard to the appearance of metastatic " tumours in the appendix" the author emphasizes that its position in the pelvis is a predisposition to metastases.

The fact that Ah1ström has dealt with the changes in the appendix without touching the question of pseudomyxoma peritonei arising from this latter organ is very interesting, because it confirms the possibility of a simultaneous existence of the tumours in the ovary and in the appendix or in both ovaries, in one of them a typical gelatinous cystoma, in the other one in its initial stage.

All of which reminds us of what was described some years later by Rathe, Eden and ourselves.

Ahlström himself could not decide whether there were metastases or the formation of a new tumour, but we think the latter supposition to be more probable; if it is true Ahlström's cases go to confirm the hypothesis that tumours identical in character with the cystoma of the ovary arise simultaneously with it or very shortly afterwards, in various parts of the body.

In cases in which there is excessive malignancy as in his fifth case and those of Westermark, Amiel, Polano and Meyer, Ahlström decided that all these cases must be acknowledged to be gelatinous 
cystomata of the ovary, benign according to their anatomical construction, but with epithelium very liable to proliferate.

In these cases the epithelium, morphologically normal, is very similar to that in colloid carcinoma owing to the method of the spreading of the metastases, and in the biological sense these cases must be considered malignant.

"Apparently (p. 224) the same epithelium identical in all cases may have in some other different liability to proliferation, and, on the other hand, the resistance of the organism has a great influence on the issue.

\section{CCNCLUSIONS.}

1. Pseudomyxoma peritonei owing to the investigations made since Fränkel's time must be divided into two kinds. The first, that arising from the bursting of a pseudomyxomatous cystoma of the ovary, and the second when the mucous matter which has been accumulated in the appendix ruptures the walls of the latter and escapes into the peritoneal cavity, later on spreading over the entire peritoneum.

2. There have been described many cases, in which the accumulation of the mucous matter resulted from both points of origin, i.e., from the cystoma of the ovary and from the appendix; sometimes the time of its origin in these points was coincident or nearly so.

3. The examination of similar cases, particularly in the earlier stages of the process, we may hope, will elucidate the nature of this disease.

4. The question of the malignancy of the pseudomyxoma of the peritoneum is very interesting, but quite enveloped in doubt, and there is a great difference between some cases, which are definitely malignant and others in which there has been no recurrence of the disease during a period of more than 17 years.

\section{LITERATURE.}

I. Abadie. "Trois cas de maladie gélatineuse du péritoine à point de départ ovarien." La Gynécologie, Sept. 1913.

2. E. Ahlström. "Ueber die Gallertkystome der Ovarien und die bei Ruptur derselben auftretenden gallertigen Veränderungen des Bauchfells" (S.G. pseudomyxoma peritonei). Diss. Stockholm, 1909.

3. Amann. Mon. f. Geburtsh. u. Gyn., Bd. xxxi, S. 324 .

4. Fred Warren Bailey. "Pseudomyxomatous Cysts of the Appendix and Ruptured Pseudomucinous Ovarian Cyst." Surgery, Gyncecology and Obstetr., vol. xxiii, August 1916, No. 2.

5. Bondy. Mon. f. Geb. u. Gyn., April 1913, Bd. xxxvii, S. 5 10. 
6. E. N. Winteler. "On the Pathology and Histology of the Cysts of the Appendix." Diss. Charkof (Russian), Igog.

7. Cramer. Mon. f. Geb. u. Gyn., i910, Bd. xxxii, S. 697.

8. Christiani. "Ueber einen Fall von Pseudomyxoma peritonei." Petersb. Medicin. Zeitschr. 1913, No. 15.

9. Thomas Watts Eden. " $A$ case of Pseudomyxoma of the Pcritoneum arising. from Perforation of a Celatinous Cyst and associated with similar Cystic Disease of the Vermiform Appendix." Lancet, 1912, vol. ii.

ro. Götte. "Leber 2 Fälle von Pseudomyxoma Peritonei." Inaug. Diss. Lcipzig, 1914. Cit. after Cramer.

11. A. Hahn. "Leber Pseudornyxoma Peritonei in anatomischer und klinischer Beziehung." Inaug. Diss. I.eipzig, r907.

12. N. J. Kedrof. "Essay of Study of the Ciganlic Tumours of the Cienitals of the Women." Diss Kazan, 1913, p. I51 (Russian).

13. Lahm. "Zur Histogenese der Pseudomucinkystome des Ovariums." Beitr. z. Geb. u. Gyn., Hegar, Bd. xix, H. 11, 1914, S. 261.

14. G. G. Levitzky. "Ein Fall von Pseudomyxoma des Raurhfelles und des Netzes." Mon. j. Geb. u. Gyn., Bd. xiv, Igox, S. 490.

15. B. M. Leontief. "Pscudomyxoma peritonei ex processu vermiformi." Russky Wratch., 1913, N. 37 (Russian).

16. Meriel E. et Daunic. "Kyste gélatineux de l'appendice." Toulouse Míd., I913. Cit. after Z. Gesammte, Gynck. u. Geburtsh. u. s. m., Bd. iv, H. 9, 1914, S. 448.

17. Meyer, M. W. "Malignes Pseudnmyxoma peritonei mit Beteiligung der Milz und des Colon." Annals of Surg., 1907. Cit. after Mon. f. Geb. u. Gyn., 1908, Bd. xxvii, H.I., S. 226.

I8. Mond. Mon. f. Geb. u. Gyn., Bd. xv, S. 122, Igoz.

19. Nagel. "Myxom. des Ovariums." Verhandl. d. VI. Intern. Kongr. f. Geb. Gyn. in Berlin 1912. Berlin, I913, S. 795 See also Zentr. J. Geb. u. Gyn., Bd. sxxvi, N. 47 , 1912, S. 1583 .

20. Nicholson, G. W., and L. Pick. "Ueber locale Destruction und multiple Lungenmetastasen beim Pseudomucinkystom des Kierstockes." Zeitschr. f. Geb. u. Gym., 1909, Bd. lxiv, S. 252 .

21. Oberndorfer. "Schleimbildung in und um Wurmfortsalzdivertikel." Verhandl. $d$. deutschen Patholog. Gesellsch. Jahrg., Igo6; Jena, I9n7, V. Sitz, xlix, S. 235.

22. Pcters. "Pseudomyxoma peritonei." Man. f. Geb. u. Gyn., x899, Bd. x.

23. Paczek. "Ein Fall von Pseudomyxombildung nach. Appendicitis." Jn. Diss. Breslau, 1912.

24. Oscar Polano. "Zur Lehre vom sngen. Pseudomyxoma peritonei." Mon. f. Geb. u. Gyn., Bd. xiii, 19nt, S. 734 .

25. Pikin, F. M. "Ein Fall von Pseudomyxuma des Bauchfells nach Appendicitis." St. Petersb. Medic. Woch. Jahrg., $x \times x v$, N. 45.

26. Orlof, G. N. "On the Account of the Cysts of the Appendix." Voenno-Medic. Journal, 1914 (Russian).

27. Rathe. "Ein Fall von Pseudomyxoma peritonei mit Betheiligung der Ovarian und der Appendix." Gyncek. Runschau, 1913, vii, Jahrg. 191 i, S. 724.

28. Rathe Mon. f. Geb. Gyn., Bd. xxxvii, 1913, H. 3, S. 322 . 
29. Simon. W. V. "Entzündliche Divertikel des Wurmfortsatzes" Berlin Klin. Wochenschr., s911, N. 33.

30. Schilling, W. "Beitrag zur Kasuistik des Pseudomyxoma peritonei." Jn. Diss., Erlangen. xg1 I.

31. Schumani, E. A. "Pscudomyxoma peritonei." Surgery, Gyncecol. and Obst., January rgog. Cit. after Mon. f. Geb. u. Gyn., Bd. xxx, Ig08, S. 505.

32. Ssysojef, T. T. " A case of Multiple Cysts of the Appendix." Russky Vratch, Igri, N. 47, p. 1796 (Russian).

33. Ssysojef, T. T. Virchow's Arch f. pathol. Anat. u. Phys., Bd. 205, $19 \mathrm{I}$.

34. Trotter. Brit. Med. Journ., vol. i, 1910, p. 245. Cit. by Wilson.

35. Wilson, Th. "Gelatinous Glandular Cysts of the Ovary and the so-called Pseudomyxoma of the Peritoneum." Proc. of the Royal Society of Med., vol. vi, Sess. 1913, Part, 11, London, 1913, p. 9.

36. Wilson, Th, Lancet, 1912, vol. ii, p. 1496.

37. Zondeck. "Appendixdivertikel und Perityphlitis." Bexl. klin. Woch., 191 1, N. 44.

38. Wienets, S. "The Clinical Malignancy of Pseudomucinous Cystadenoma of the Ovary." Amer. Journ. of Obst., etc., June 1914 . 